\title{
Research Paper: The Study of the Emotion Recognition and the Cognitive Failures of Children With Developmental Coordination Disorder
}

\author{
Leyla Vatandoust ${ }^{1}(\mathbb{D})$, Ramazan Hasanzadeh ${ }^{1^{*}(\mathbb{C})}$
}

1. Department of Psychology, Faculty of Humanities, Sari Branch, Islamic Azad University, Sari, Iran.

Citation: Vatandoust L, Hasanzadeh R. The Study of the Emotion Recognition and the Cognitive Failures of Children With Developmental Coordination Disorder. Iranian Rehabilitation Journal. 2018; 16(2):121-130. http://dx.doi.org/10.32598/irj.16.2.121

http://dx.doi.org/10.32598/irj.16.2.121

Article info:

Received: 05 Jan 2018

Accepted: 10 Apr 2018

\section{Keywords:}

Emotion recognition, Cognitive failures, Developmental coordination disorder, Children

\section{A B S T RACT}

Objectives: Recently, attention has been paid to the Developmental Coordination Disorder (DCD) in children. DCD occurs silently in child development stages; the child is involved with deficiencies that affect his / her social relationships, academic achievement and emotional perception. In this study, we tried to investigate the state of emotion recognition and the cognitive profiles of the children. The purpose of this study was to investigate the emotion recognition and cognitive failures of children with DCD.

Methods: This was a descriptive and correlational study. The research sample included 120 students with a developmental coordination disorder. The research tools were Battery test: The Cambridge Mindreading (CAM) Computer Version of Revised Reading the Mind in the Eye Test; The Movement Assessment Battery for Children-Second Edition (MABC-2) skills. For data analysis, confirmatory factor analysis for DCD model was done by using Laserl.

Results: The results of the confirmatory factor analysis indicate the fitness of the model The second root of the squared mean of the test of the case model is closer to zero. This difference is between the predicted value of the model or the estimator and the actual value. That is, estimating the model is near to actual value, therefore the model is approved. In this model, some amount of inertia RMR (0.55) and SRMR (0.666) was an indication of the proper explanation of covariance.

Discussion: Study of the state of emotion recognition in children with DCD can help us to provide training programs, therapy and counseling to improve their social skills, selfconfidence and academic achievement.

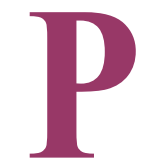

\section{Introduction}

oor motor performance was observed in children for many years, even before 1937, and they were categorized as clumsy children (Raw Motorized) [1]. In a developmental coordination disorder, despite the healthy functioning of the sensory-motor nervous system, the movements are not carried out skillfully

* Corresponding Author:

Ramazan Hasanzadeh, PhD

Address: Department of Psychology, Faculty of Humanities, Sari Branch, Islamic Azad University, Sari, Iran.

Tel: +98 (911) 3232106

E-mail: hassanzadehd@yahoo.com 
in a coordinated manner. Of course, all the daily activities of life are affected by targeted motor skills.

Motor coordination impairment may be associated with problems concerning gross motor skills, fine motor skills, or both [2]. Some children may have balanced weakness and others may have reached their developmental milestones later than their peers [3]. In some cases, there is a delay in children's motor growth as compared to their peers, who are growing in a balanced manner. The studies been done to describe the coordination problems of these children have shown that these children, as a group with slower motor function, less precision in reviewing the content, are less accurate and more unstable than their peers [4].

The ability to understand the emotional and mental states of others is the basis of social skills and a key process for empathy [4]. The ability to distinguish emotions begins from the first year of life. For example, 10-weekold children show different reactions to the emotional states of their caregiver whether in the face or in the sound [5]. Seven months old babies can recognize facial and emotional emotions. Three and two year old children use words that have a psychological state in their speech. In childhood, the accuracy and speed of Emotion Recognition (ER) improves. By the age of seven, the children's emotional words increase and they can identify mental states more precisely [6]. The emotional cognitive skills and psychological states of adolescence also persist. This emotion recognition is the ability to reason others' mental state and it includes the ability to maintain belief about beliefs or present the mental representations of others [7]. We believe in emotion recognition and that emotions are a precondition to understand the social environment and involve in competitive social behaviors. Emotions are an important part of social communication and people become aware of it without really talking about the situations, desires, concerns, intentions of the others, through facial expressions $[8,9]$.

On the other hand, complex emotions include a different physical evaluation and cognitive activity in the cortex that comes with a combination of basic emotions. Secondary emotions (complex emotions) arise during growth and show the individual and cultural diversity, and are more sensitive to the more complex and abstract features of specific stimuli [10]. In general, complex emotion involves describing a cognitive state plus a feeling that is more related to the context and is culture- based [10]. Complex emotion may be a belief that is more situation-based, for example, frustration. It may also be a self-conscious feeling, such as pride or embarrassment [11]. Identification of specific cognitive profiles (strengths and weaknesses) can lead to the discovery of appropriate strategies for Developmental Coordination Disorder (DCD) children's education and provide a platform for evaluating the consequences of implemented interventions.

Studies show that Developmental Coordination Disorder (DCD) children have significant problems with learning, social skills, and self-confidence. Crane et al [12] argued that besides motor impairments, children with DCD show high rates of psychopathology such as anxiety and low self-esteem. They argue there is a need to monitor the levels of emotional and behavioral problems among children with DCD, from multiple informants. Also Rahimi-Golkhandan et al [13] showed that children with motor coordination problems (or developmental coordination disorder - DCD) have deficits in not only the cool Executive Function (EF) but also hot EF. They showed that DCD group made significantly more commission errors to happy faces, failing to suppress their response on more than half of the no-go trials. These results suggest a heightened sensitivity to emotionally significant distractors in DCD. They argue that the interaction of cognitive control and emotion processing networks may be disrupted in DCD or delayed in development.

On the other hand, research literature suggests that cognitive development and motor function are dependent on each other and both follow a similar growth path [14]. Piaget's early theories [15] also confirm that motor and cognitive systems work together at an early age because the child, through the work and manipulation of objects, provides information about the surroundings.

Alloway and Archibald [16] discussed the pattern of correlations between the memory and learning measures and stated that they differed between children with Developmental Coordination Disorder and specific language impairment. They argued DCD children are as LD children and have learning problems.

A recent review was done on children having four to sixteen years of growth and it showed that the development of motor skills is often associated with stronger performance in cognitive tasks [17]. So, understanding this relationship in the DCD children can also be important in educational work and the diagnostic process.

The purpose of this study was to investigate the Emotion Recognition (primary and secondary emotions), cognitive failures and their impact on MABC-2 skills (learn- 
ing, self-confidence and social relationships) of children having the developmental coordination disorder.

\section{Methods}

This was a descriptive and correlational research. The population consisted of all elementary school students in the $2^{\text {nd }}$ district of Tehran, during the academic year of 2017. The prototype was selected from this community $(n=4000)$. The sample included 180 students, with developmental coordination disorder and they were selected as follows:

At first, the list of all elementary schools' students in Tehran's $2^{\text {nd }}$ district was collected. Out of the ordinary schools and exceptional schools, a total of 18 elementary schools (8 ordinary schools and 8 exceptional schools) were chosen and from each school one first grade class and one second grade class was selected randomly. After coordinating with the parents and teachers' community of selected schools, for parental cooperation in completing the Development Coordination Disorder Questionnaire, the questionnaire was sent to the parents of the selected students. Also, Self-Perception of Adequacy in Predilection for Physical Activity (CSAPPA) was used as a supplement to identify students with developmental disorder symptoms. Also, after completing the parental and student version checklist the latest version of the motor skills test kit (ABCM-2) was conducted to assess motor skills. The sample included 120 students, with developmental coordination disorder and they were selected as follows:

\section{Battery Test: The Cambridge Mindreading (CAM) Face-Voice Battery}

Emotional development classification has nine concepts: entertained, annoyed, disappointed, embarrassed, jealous, lovely, nervous, hesitate, and hostile. In addition it has subtle versions of the basic emotions that have a psychological component, as well the emotions and mental states that are essential for the daily social function scale. For each of the emotional concepts, there are three facial and three auditory items using silent video clips from facial expressions and audio clips in which a short sentence with an emotional pitch of the voice (3 to 5 seconds) is said. In the CAM-C test, audio and video clips are taken from an interactive guide for emotion [11]. In this test, voices and images are performed by male and female professional actors from different age and ethnic groups (Figure 1).

In CAM-C, using the emotional classification, there are three foils for each scale. The selected foils are either at the same level of growth or at a simpler level than the target's emotion. Selected foils for audio items are selected in the way that are matched with the verbal content but do not match with the emotional intonation. For example, the sentence "You could do it again" which is performed with the intonation of "happy" voice, has three foils - "interested", "hesitant" and "thinking". During the construction phase of this test two judges independently reviewed all the foils to conclude that the foils do not look very similar to the desired emotion. In this test two scales, one for face recognition and one for audio recognition were built using the experimental soft-
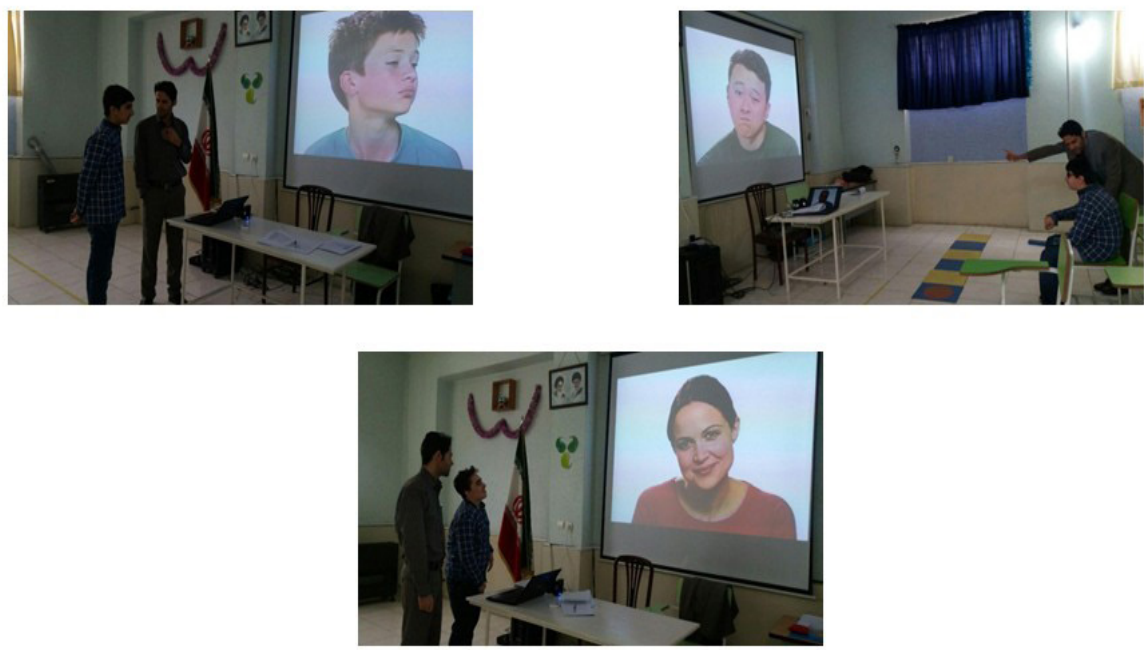

Figure 1. The Cambridge Mindreading (CAM) face battery 
ware DMDX [11]. Each scale begins with a slide of the instruction that asks the subjects to describe the person's feelings shown in the clip, in the best way. After this instruction, two practical items are played.

On the facial scale, four emotional options, from 1 to 4 , are shown after each clip. Items are shown in random order. On the audio scale, these four options in reply, before and during item playback, are shown to avoid excessive loading memory retrieval of the subject. This scale causing random playback of audio items was not possible. Instead, two versions of the audio scale are provided having their arrangements are opposite to each other. So in this way, the effect of the order is prevented. In the study, they provided a brochure containing definitions of all the emotional words used in these scales. Then, these scales were performed on 16 children - including two girls and two boys from four different age groups. Prior to participating in this test, the parents of the children gave written consent and their children's oral satisfaction was obtained. These children were selected from a local elementary school and were tested individually there. The test was performed through laptops and using headphones for audio scales. The examiner read the instructions to prevent confusion caused by reading difficulties, then used the pamphlet to be sure that the children understood all the words correctly. The subjects were then asked to press keys 1 to 4 to select their response. During the test, no feedback was given to the children. Following this, an items analysis was carried out.

In research done by Golan et al. [6], subjects scored on an average $16.89(\mathrm{SD}=4.36)$ in face recognition and 18.07 $(\mathrm{SD}=3.97)$ in voice recognition, as well as an average of 5.49 ( $\mathrm{SD}=2.08$ ) for recognizing the emotional concept correctly. Also, CAM-C scores were positively correlated in face ratio $(\mathrm{r}=0.60, \mathrm{P}<0.001)$. The scales $(\alpha=0.01)$ indicated that they could well distinguish between the control group and the ASC group: $1-\beta=0.951$ for the face recognition, 0.923 for the audio recognition, and 0.949 for the number of emotions that were recognized correctly. To examine the test-retest reliability, 21 ASC children filled out the CAM-C test twice and there were 10 and 15 weeks interval between the two measurements.

\section{Computer Version of Revised Reading-the-Mind- in-the-Eye Test}

To measure mind-reading, Baron-Cohen's Computer Version of Revised Reading-the-Mind-in-the-Eye Test is used. The revised version of this test has 36 items that include photographs of the male and female artists. With each question, four descriptions of the mental state (a tar- get state and three deviant modes with the same emotional value) are presented. Only by using visual information, respondents are asked to choose the word that best describes their mind or feelings. For scoring, score 1 is assigned for each correct answer and the scores range from 0 (zero) to 36. A score of less than 22 indicates a moderate mind-reading and a score of over 30 indicates low-mind reading,while a score between 22 to 30 is a high-mind reading indicator. The validity and internal consistency of this test has been reported in good rate [18].

\section{Cognitive Failures Questionnaire}

The Cognitive Failure Questionnaire was created in 1982 by Bradbent, Cooper, Fitzgerald and Paracs. This scale has 24 items and its items are scored on a five-point scale - from "Never" being represented as grade 5 to "Always" being represented as grade1. This questionnaire has four components: distraction, memory problems, mistakes in vain, and lack of name reminders. In Wallace's survey, the Cronbach's alpha coefficient was 0.96 and its coefficient of validity was 0.51 [19]. In a preliminary study, internal consistency of the coefficient and test-retest reliability coefficient of cognitive failure were reported to be 0.89 and 0.77 , respectively.

\section{The Movement Assessment Battery for Children- Second Edition (MABC-2) skills}

MABC-2 includes three parts: A standardized test, a checklist, and a user guidebook in which an environmental approach is described for the treatment of children with motor problems (El Guidebook). In MABC-2 test and check list, the identification and description of motor disorders in children have been considered mainly, while the test and checklist are complementary in terms of data collection methodology. The MABC-2 test is a standard test that requires performing a series of motor tasks in the manner prescribed for the child [20]. In addition, this test provides qualitative information on how these tasks are performed by the child. It is divided into three age groups (AB): $A B$ 1: 3 to 6 years old; $A B$ 2: 7 to 10 years old; $A B$ 3: 11 to 16 years old. I $n$ the test, the child is directly involved, while in the checklist another person assesses the child's motor ability (Figure 2). The Movement Assessment Battery for Children-Second Edition (MABC-2) evaluates also the non-motor skills, which include three sub-variables of social skills, learning and self-confidence. The MABC-2 checklist has been designed to provide information on children suspected of having a non-movement difficulty. This is done on the basis of a list of specific motor behaviours that can be observed in the everyday setting such as a classroom 

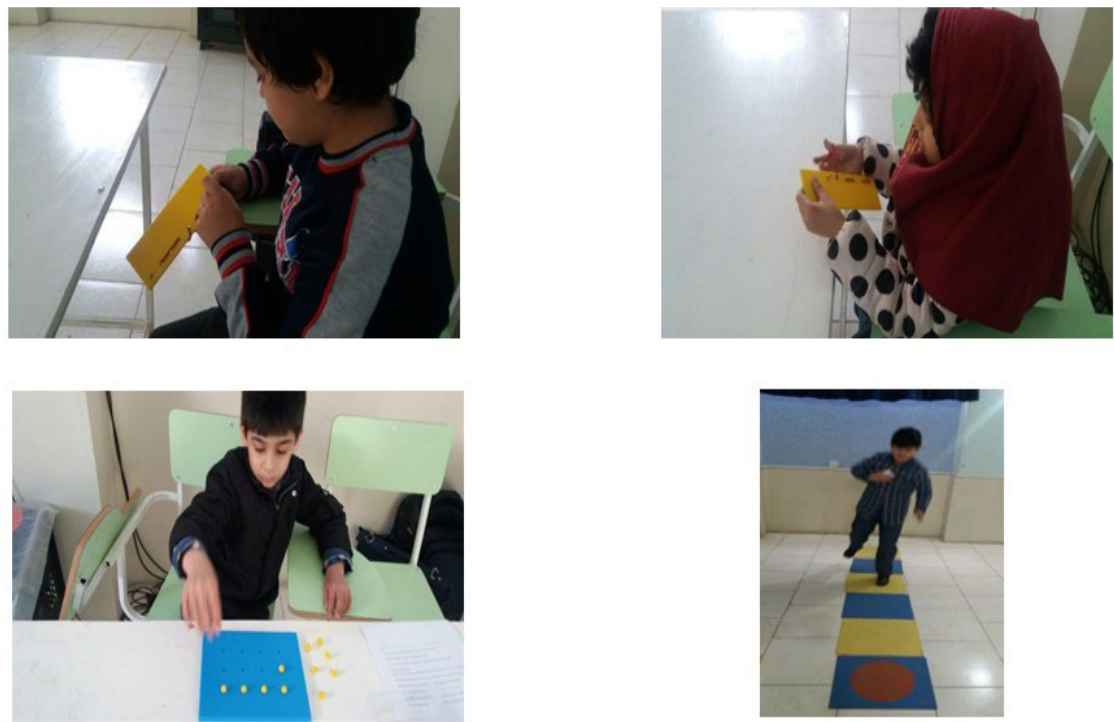

Figure 2. The movement assessment battery for children-second edition

or playground. An adult observer rates a child's performance during each time in the checklist, in terms of how competency is executed. Some motor problems cause non-motor problems and respectively.

In each age group, eight tasks (items) are grouped under three headings - manual skill, targeting and catching, and balance. Depending on the child's age, the difficulty that the child experienced and also the experience of the examiner takes 20 to 40 minutes to complete these eight tasks. So the objective and quantitative information on motor ability is provided. In each item, the offered standard score for each age group is between 4 and 16, and for the half-year groups it is between 3 and 4. Scores and standard percentages of related ages are given for these three parts of the test (manual skill, targeting and catching, and balance) as well as the total score. In addition, the total score can be interpreted in the form of a traffic lights system, which includes three zones. If the score is in the green zone it indicates that the child's performance is within the normal range. The yellow zone is assigned to a group that is at risk and shows that the child needs precise monitoring. The red area indicates a definite motor disorder. Since the boundaries of these three areas are identical in the test and checklist, if needed, the obtained results can be directly compared [20].

\section{Results}

The Table 1 shows Pearson Correlation Coefficients for examining the relationship between hidden variables. On the main axis of this matrix, there is a number 1 in which each variable is completely correlated. Most of these correlation coefficients are significant at $95 \%$ confidence level ( $>5 \%$ ). The positive coefficient indicates a positive and direct relationship between the two variables.

\section{Confirmatory Factor Analysis for DCD Children}

Figure 3 shows the model of confirmatory factor analysis for DCD children in the mode of estimating standard coefficients. In Figure 3, the standard mode of coefficients for DCD children is observed.

Table 1. Correlation matrix between DCD childhood hidden variables

\begin{tabular}{cccc}
\hline Hidden Variables & MABC-2 Skills & Cognitive Failure & Emotion Cognition \\
\hline MABC-2 skills & 1 & 1 & \\
Cognitive failure & -0.465 & -0.697 & 1 \\
\hline Emotion cognition & 0.490 & Пranian Rehabilitation Journal
\end{tabular}

All starred coefficients $\left({ }^{*}\right)$ are significant at $95 \%$ confidence level. 


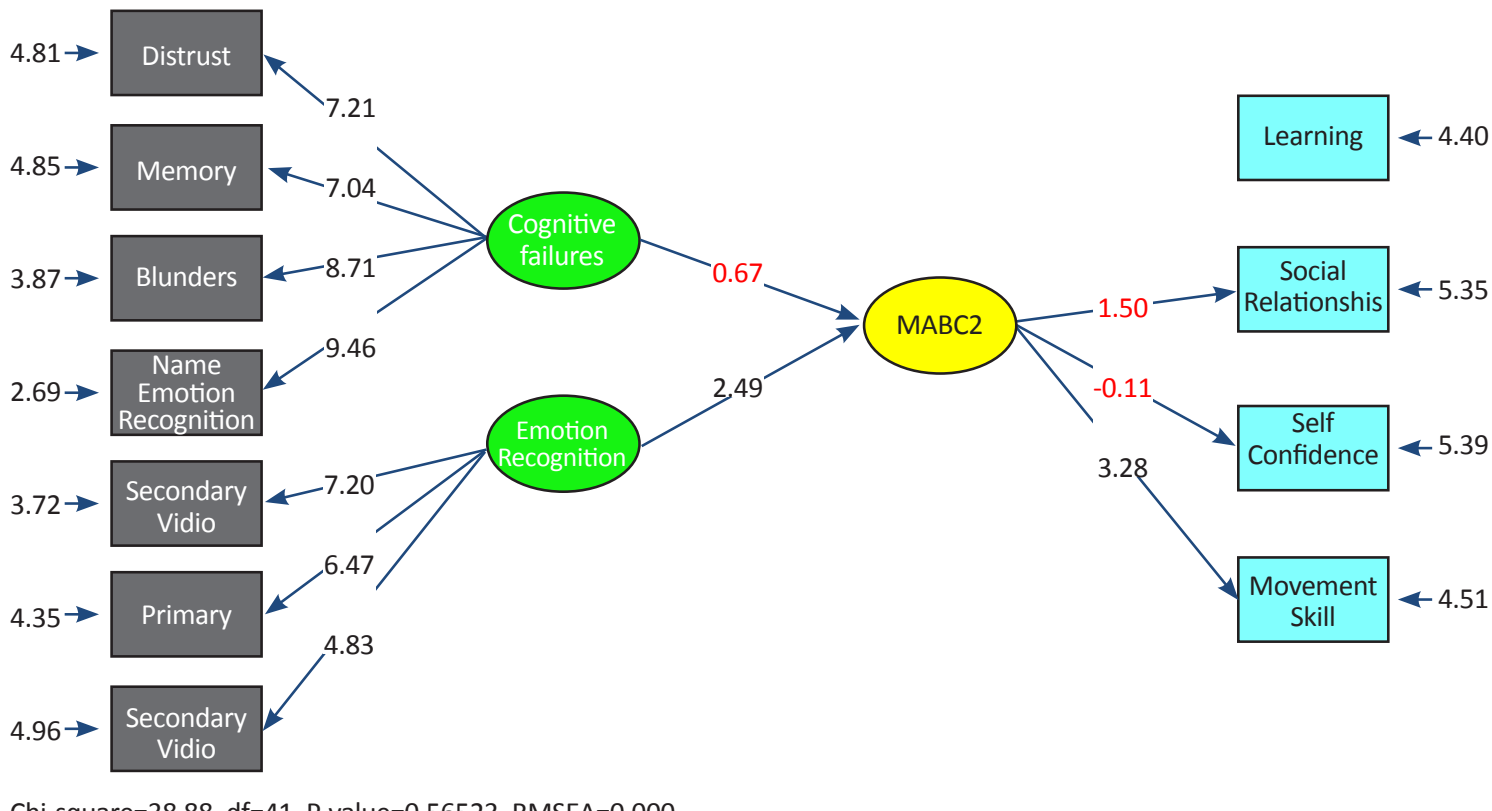

Chi-square $=38.88, \mathrm{df}=41, \mathrm{P}$-value $=0.56523, \mathrm{RMSEA}=0.000$

IIranian Rehabilitation Journal

Figure 3. Confirmatory factor analysis model for DCD children in the mode of estimating standard coefficients

As you know, learning has the most impact on MABC-2 skills. Also, memory problem has the greatest impact on cognitive failures and basal emotions have the greatest impact on emotional recognition. Between the two factors of cognitive failures and emotion recognition, the factor of emotional recognition has a greater impact on MABC-2 skills.

In Figure 4, the standard t-value coefficients were used. This test examines factors that have significant effect. The coefficients marked in red color do not have a significant effect.

\section{Interpretation of the model for DCD children}

In this model, the amount of $\mathrm{NaCl} \mathrm{RMR}(0.55)$ and SRMR (0.666) indicate a proper explanation for covariance. As the characteristics of fitness at the bottom of the models and Tables 2 and 3 are written and they

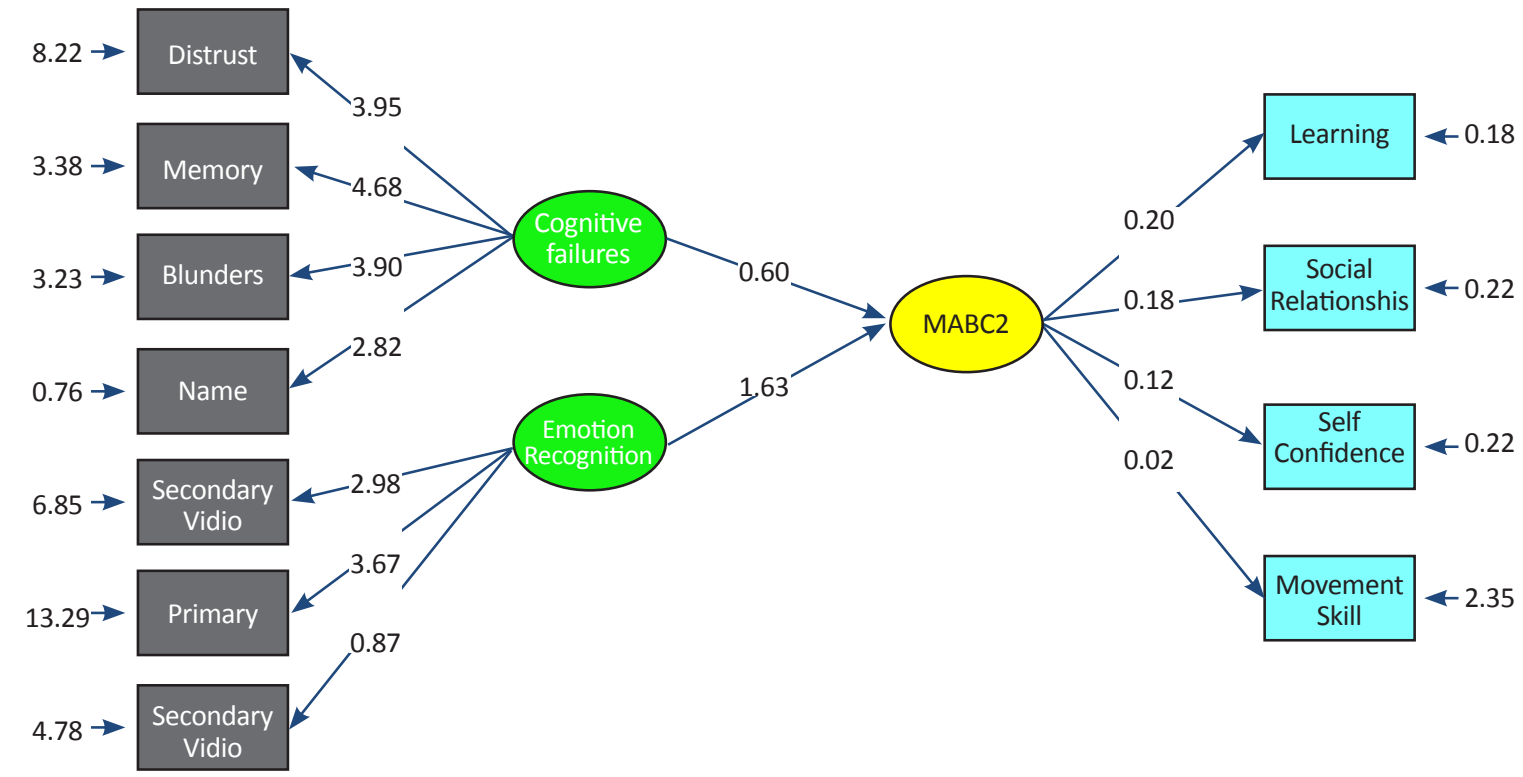

Chi-square $=46.89, \mathrm{df}=41, \mathrm{P}$-value $=0.24374, \mathrm{RMSEA}=0.049$

Figure 4. Confirmatory factor analysis model for DCD children in significant statement (t-value) 
Table 2. Model fitting indices for DCD children

\begin{tabular}{ccc}
\hline Index Name & Model Estimates & Limit \\
\hline Chi-2 degree of freedom & 1.38 & $<2$ \\
GFI (Goodness of Fit Index) & 0.89 & $0.9<$ \\
RMSEA (The Root Mean Square Error of Approximation) & 0.054 & $<0.1$ \\
CFI (Comparative Fit Index & 0.98 & $0.9<$ \\
NFI (Normed Fit Index) & 0.92 & $0.9<$ \\
NNFI (Non-Normed Fit Index) & 0.97 & $0.9<$ \\
IFI (Incremental Fit Index) & 0.98 & $0.9<$ \\
\hline
\end{tabular}

Пranian Rehabilitation \ournal

indicate that the data of this research is relatively well suited to the structure of the factor and the theoretical basis of the research. This suggests that it is consistent with theoretical structures.

To construct the model and discover the constituent of the elements, the confirmatory factor analysis was used. The results of the confirmatory factor analysis for DCD children are summarized in the table above. Factor loads related to the research factors were all tested at the error rate of $5 \%$. All factor loads of this variable were significant at $95 \%$ confidence level ( $\mathrm{T}$ intervals ranged from +1.96 to -1.96 ). Except the load factor of self-confidence, all others have been able to make a significant contribution to measuring the structure. An index that has a higher load factor has played a main role in measuring the structure. Learning index, memory problem, and basic emotions have had the largest contribution in explaining the variables. The mean value of the extracted variance indicated that, except the MABC-2 skills, all study structures had the Average Variance Extracted (AVE) higher than 0.5.

\section{Discussion}

The results of this study and confirmatory factor analysis indicate the fitness of the model. As mentioned in the Results, the second root of the mean square for the test of case model is closer to Zero. In this model the amount of RMR and SRMR shows a proper explanation of co-

Table 3. Confirmatory factor results for the DCD model (loading factor)

\begin{tabular}{|c|c|c|c|c|c|c|}
\hline Hidden Variable & Observed Variables & $\begin{array}{l}\text { Factor } \\
\text { Load }\end{array}$ & Statistics t & $\begin{array}{c}\text { Significance } \\
\text { Level }\end{array}$ & Result & $\begin{array}{c}\text { Mean Explained Vari- } \\
\text { ance (AVE) }\end{array}$ \\
\hline \multirow{3}{*}{ MABC-2 skills } & Learning & 0.22 & 0.000 & $0.05>$ & Meaningful & \multirow{3}{*}{0.081} \\
\hline & Social relation & 0.17 & 2.17 & $0.05>$ & Meaningful & \\
\hline & Self confidence & 0.11 & 1.54 & $0.05>$ & Meaningful & \\
\hline \multirow{5}{*}{ Cognitive failure } & Distractions & 3.86 & 9.09 & $0.05>$ & Meaningful & \multirow{5}{*}{29.836} \\
\hline & Memory problem & 4.65 & 9.53 & $0.05>$ & Meaningful & \\
\hline & & & & & & \\
\hline & Mistakes in vain & 3.92 & 7.57 & $0.05>$ & Meaningful & \\
\hline & No reminder & 2.79 & 9.92 & $0.05>$ & Meaningful & \\
\hline \multirow{3}{*}{ Emotion cognition } & Basic emotions & 3.64 & 5.90 & $0.05>$ & Meaningful & \multirow{3}{*}{7.299} \\
\hline & Sophisticated visual emotion & 2.79 & 5.90 & $0.05>$ & Meaningful & \\
\hline & Sophisticated audio emotion & 0.93 & 3.06 & $0.05>$ & Meaningful & \\
\hline
\end{tabular}


variance. Factor loads of the research factors have all been tested at a 5\% error rate. All factor loadings of this variable are significant at $95 \%$. As the characteristics of fitness written below the models and the following table show that the data of this research along with the structure of the factor and theoretical basis of research have a fairly fitness and this indicates that it is consistent with the theoretical constructs. Results showed that students with a developmental coordination disorder have more cognitive failures.

In line with these findings, a research has shown that DCD children have extensive performance problems. Similarly, attention problems have been reported in DCD children [3]. Therefore, poor attention may affect the performance of the working memory, because the ability to focus and process the information selectively will definitely effect on how this information remains in their working memory. Alloway and Temple [21] indicated that children with DCD showed impairment in all the four areas of memory function. They argued the deficit in memory among children with DCD is linked with movement planning and control and overlap with cognitive resources allocated to generating movement.

It was also found that the DCD students have social problems including significant weaknesses of self-esteem. Sumner et al. [22] examined the cognitive abilities among children with DCD and healthy children. The results showed that DCDs in WMI and PSI in Wechsler were lower than healthy children. These children also had a significant weakness in two sub-tests: digit and coding test. DCD children as a group had more varied patterns of performance in cognitive domains, while the performance of healthy children in these areas was nearly the same. In particular, the performance of DCD children in VCI and PRI was significantly better than their performance in PSI. However, it is important to note that the performance of the DCD group was within the average range of indices and sub-tests. So it can be pointed out that in addition to having some cognitive and processing problems, and children having motor learning problems due to these, it causes reduction of their ability to face exposure to the environment and compromises their emotional and social development. Studies showed that DCD children have comorbid disorders such as learning problems $[23,24]$.

Motor activity such as serialization, categorization [21] and counting [25] requires development of mathematics and subjective representation of concepts. Therefore, it can be concluded that learning difficulties in children with DCD and their communication skills consider self-confidence as a moderating variable that does not strengthen these skills in people who are affected. This factor can be seen in the present study model. It was also found that the DCD children have shortcomings in communicating and understanding emotions, especially the complex emotions. The existence of this shortcoming leads to a lack of proper communication and results in poor interpersonal and social relationships and low selfconfidence in these children. Therefore, the greater the emotion (primary and secondary) recognition, the stronger will be the social relationships and self-esteem, thus they will be more involved. Therefore, it is suggested that in future research other aspects of developmental coordination disorder should be addressed. Considering the disruptive effect of this disorder on strengthening social educational skills, these people will be examined at higher educational levels in order to provide them the necessary educational and therapeutic programs. It is also suggested that more precise measurement and evaluation tools (including the MABC- 2 battery test kit used in the present study for the first time in Iran) should be used to diagnose the developmental coordination disorder so that the affected children are provided consultations, evaluated and treated.

\section{Conclusion}

The present study showed that students with developmental coordination disorder, in addition to motor learning problems that reduce the ability to deal with the environment and compromise their emotional and social development, are also involved in the problem of cognitive impairment. DCD can be associated with problems in planning, attention and simultaneous coding that may lead to learning disabilities. The ability of information processing has a significant role in movement domain as well as in cognition. The lack of understanding of emotions (especially complex emotion), lack of appropriate communication, and consequently poor interpersonal and social relationships, as well as low self confidence in DCD individuals can be predicted.

\section{Ethical Considerations}

\section{Compliance with ethical guidelines}

This paper was approved by ethics and research committee of Islamic Azad University, Sari Branch with the code number of 25763-3. Leyla Vatandoust collected the clinical data; conceived and designed the study and also drafted as well as revised the manuscript. Ramazan Hasanzadeh performed the statistical analysis and re- 
vised the final manuscript. All authors read and approved the final manuscript.

\section{Funding}

The present study is extracted from the $\mathrm{PhD}$ thesis of Ramazan Hasanzadeh in Islamic Azad University, Sari Branch with the code number of 25763-3, in 2016.

\section{Conflict of interest}

The authors declared no conflict of interest.

\section{Acknowledgements}

We are grateful to the honorable authorities of elementary schools of Tehran District 2, the students and their dear parents, who have completely cooperated with us throughout all stages of the research.

\section{References}

[1] Kaplan BJ, Wilson BN, Dewey D, Crawford SG. DCD may not be a discrete disorder. Human Movement Science. 1998; 17(4):471-90. [DOI:10.1016/S0167-9457(98)00010-4]

[2] American Psychiatric Association. Diagnostic and statistical manual of mental disorders (DSM-5®). Washington, D.C.: American Psychiatric Pub; 2013. [DOI:10.1176/appi. books.9780890425596]

[3] Dewey D, Wilson BN. Developmental coordination disorder: what is it. Physical \& Occupational Therapy in Pediatrics. 2001; 20(2-3):5-27. [PMID]

[4] Blank R, Smits Engelsman B, Polatajko H, Wilson P. European Academy for Childhood Disability (EACD): Recommendations on the definition, diagnosis and intervention of developmental coordination disorder (long version). Developmental Medicine \& Child Neurology. 2012; 54(1):54-93. [DOI:10.1111/j.1469-8749.2011.04171.x] [PMID]

[5] Harms MB, Martin A, Wallace GL. Facial emotion recognition in autism spectrum disorders: A review of behavioral and neuroimaging studies. Neuropsychology Review. 2010; 20(3):290-322. [DOI:10.1007/s11065-010-9138-6] [PMID]

[6] Golan O, Sinai Gavrilov Y, Baron Cohen S. The Cambridge Mindreading Face-Voice Battery for Children (CAM-C): Complex emotion recognition in children with and without autism spectrum conditions. Molecular Autism. 2015; 6(1):22. [DOI:10.1186/s13229-015-0018-z] [PMID] [PMCID]

[7] Castelli F. Understanding emotions from standardized facial expressions in autism and normal development. Autism. 2005; 9(4):428-49. [DOI:10.1177/1362361305056082] [PMID]

[8] Wellman HM, Cross D, Watson J. Meta-analysis of theory-ofmind development: The truth about false belief. Child Devel- opment. 2001; 72(3):655-84. [DOI:10.1111/1467-8624.00304] [PMID]

[9] Aljojo N, Saifuddin H. Testing complex emotion recognition in adults: A gendered comparison. International Journal of Computer Applications. 2015; 122(12):49-55. [DOI:10.5120/21756-5062]

[10] Griffiths PE. III. Basic emotions, complex emotions, machiavellian emotions. Royal Institute of Philosophy Supplements. 2003; 52:39-67. [DOI:10.1017/S1358246100007888]

[11] Golan O, Baron Cohen S, Golan Y. The 'reading the mind in films' task [child version]: Complex emotion and mental state recognition in children with and without autism spectrum conditions. Journal of Autism and Developmental Disorders. 2008; 38(8):1534-41. [DOI:10.1007/s10803-007-0533-7] [PMID]

[12] Crane L, Sumner E, Hill EL. Emotional and behavioural problems in children with Developmental Coordination Disorder: Exploring parent and teacher reports. Research in Developmental Disabilities. 2017; 70:67-74. [DOI:10.1016/j. ridd.2017.08.001] [PMID]

[13] Rahimi-Golkhandan S, Steenbergen B, Piek J, Wilson P. Reprint of "Deficits of hot executive function in developmental coordination disorder: Sensitivity to positive social cues". Human Movement Science. 2015; 42:352-67. [DOI:10.1016/j. humov.2015.06.004] [PMID]

[14] Smits Engelsman B, Hill EL. The relationship between motor coordination and intelligence across the IQ range. Pediatrics. 2012; 130(4):e950-e6. [DOI:10.1542/peds.2011-3712] [PMID]

[15] Smits Engelsman B, Schoemaker M, Delabastita T, Hoskens J, Geuze R. Diagnostic criteria for DCD: Past and future. Human Movement Science. 2015; 42:293-306. [DOI:10.1016/j.humov.2015.03.010] [PMID]

[16] Alloway TP, Archibald L. Working memory and learning in children with developmental coordination disorder and specific language impairment. Journal of Learning Disabilities. 2008; 41(3):251-62. [DOI:10.1177/0022219408315815] [PMID]

[17] van der Fels IM, te Wierike SC, Hartman E, ElferinkGemser MT, Smith J, Visscher C. The relationship between motor skills and cognitive skills in 4-16 year old typically developing children: A systematic review. Journal of Science and Medicine in Sport. 2015; 18(6):697-703. [DOI:10.1016/j. jsams.2014.09.007] [PMID]

[18] Fernández Abascal EG, Cabello R, Fernández Berrocal P, Baron Cohen S. Test-retest reliability of the 'Reading the Mind in the Eyes' test: a one-year follow-up study. Molecular Autism. 2013; 4(1):33. [DOI:10.1186/2040-2392-4-33] [PMID] [PMCID]

[19] Wallace JC. Confirmatory factor analysis of the cognitive failures questionnaire: Evidence for dimensionality and construct validity. Personality and Individual Differences. 2004; 37(2):307-24. [DOI:10.1016/j.paid.2003.09.005]

[20] Henderson S, Sugden S, Barnett A. Movement assessment battery for children: Examiner's manual. London: Pearson Education; 2007

[21] Alloway TP, Temple KJ. A comparison of working memory skills and learning in children with developmental coordination disorder and moderate learning difficulties. Applied 
Cognitive Psychology. 2007; 21(4):473-87. [DOI:10.1002/ acp.1284]

[22] Sumner E, Pratt ML, Hill EL. Examining the cognitive profile of children with developmental coordination disorder. Research in Developmental Disabilities. 2016; 56:10-7. [DOI:10.1016/j.ridd.2016.05.012] [PMID]

[23] Stephenson E, Chesson R. 'Always the guiding hand': Parents' accounts of the long-term implications of developmental co-ordination disorder for their children and families. Child: Care, health and development. 2008; 34(3):335-43. [DOI:10.1111/j.1365-2214.2007.00805.x]

[24] Kirby A, Sugden DA. Children with developmental coordination disorders. Journal of the Royal Society of Medicine. 2007; 100(4):182-6. [DOI:10.1258/jrsm.100.4.182] [PMID] [PMCID]

[25] Watemberg N, Waiserberg N, Zuk L, Lerman Sagie T. Developmental coordination disorder in children with attentiondeficit-hyperactivity disorder and physical therapy intervention. Developmental Medicine \& Child Neurology. 2007; 49(12):920-5. [DOI:10.1111/j.1469-8749.2007.00920.x] [PMID] 